J. Clin. Chem. Clin. Biochem.

Vol. 24, 1986, pp. 119-124

(C) 1986 Walter de Gruyter \& Co. Berlin - New York

\title{
Neopterin as Tumour Marker Serum and Urinary Neopterin Concentrations in Malignant Diseases
}

\author{
By $R$. Kuzmits, H. Ludwig
}

II. Department of Medicine

Elisabeth Legenstein, T. Szekeresz

Department of Medical Chemistry

C. Kratzik and J. Hofbauer

Department of Urology

University of Vienna, Vienna, Austria

(Received July 6/October 25, 1985)

Dedicated to Professor Dr. E. Kaiser on the occasion of his 60th birthday

Summary: Serum and urinary neopterin concentrations were measured in 142 patients suffering from various malignant diseases. Increased serum and urinary neopterin levels were found in $48 \%$ and $55 \%$ of patients respectively. Neopterin showed sufficient sensitivity in the detection of haematological disorders and hypernephroma, whereas the sensitivity of neopterin was rather poor in patients with other solid tumours. Comparison of serum $\alpha$-fetoprotein (AFP) and human chorionic gonadotropin (HCG) concentrations and serum or urinary neopterin levels in testicular cancer patients showed that determination of neopterin provides no further information in the management of these patients.

In testicular cancer patients receiving adjuvant chemotherapy, a significant increase in serum $(p<0.005)$ and urinary $(p<0.0005)$ neopterin concentrations was measured after chemotherapy, reflecting the release of neopterin from macrophages during the damage by cytotoxic drugs. In the adjuvant testicular tumour patients, known to be tumour free, 1 out of 16 patients showed elevated serum and 3 out of 15 patients showed false positive urinary neopterin levels.

False positive serum $(24 \%)$ and urinary $(37 \%)$ neopterin values were also obtained in 28 patients with various nonmalignant diseases, but no evidence for an inflammatory process. In 23 patients with inflammatory diseases pathological serum and urinary neopterin levels were measured in $55 \%$ and $59 \%$ respectively.

When a RIA was compared with a HPLC method, higher urinary neopterin values were obtained with the RIA, indicating that non-oxidized pterines are also determined by the RIA method.

In conclusion, neopterin might be a helpful biological marker in monitoring patients with malignant haematological disorders and renal cell carcinoma, but provides no additional information in other solid tumours studied. 


\section{Neopterin als Timormarker: Neopterinkonzentrationen in Serum und Harn bei malignen Erkrankungen}

Zusammenfassung: Neopterin wurde bei 142 Patienten mit verschiedenen malignen Erkrankungen im Serum und im Harn bestimmt. Erhöhte Neopterinkonzentrationen im Serum wurden bei $48 \%$ der Patienten beobachtet, eine gesteigerte Neopterinausscheidung im Harn wurde bei $55 \%$ der Patienten gemessen. Die Sensitivität von Neopterin war bei hämatologischen Erkrankungen und bei Patienten mit Hypernephromen ausreichend, während bei anderen soliden Tumoren die Sensitivität von Neopterin nur 'gering war. Der Vergleich von $\alpha$-Foetoprotein (AFP) und humanem Choriongonadotropin (HCG) mit Neopterinkonzentrationen in Serum und Harn bei Patienten mit Hodentumoren zeigte, daß die Bestimmung von Neopterin keine zusätzlichen Informationen bei der Behandlung dieser Patienten bringt. Bei Patienten mit Hodentumoren wurde nach adjuvanter Chemotherapie ein signifikanter Anstieg der Neopterinkonzentrationen in Serum $(p<0,005)$ und Harn $(p<0,0005)$ beobachtet, der auf die chemotherapiebedingte Zerstörung von Makrophagen mit nachfolgender Freisetzung von Neopterin zurückzuführen ist. Bei 1 von 16 Patienten mit Hodentumoren wurden vor der adjuvanten Chemotherapie erhöhte Neopterinwerte im Serum gemessen, 3 von 15 Patienten zeigten falsch positive Neopterinkonzentrationen im Harn.

Von 28 Patienten mit verschiedenen nichtmalignen Erkrankungen ohne Hinweis auf einen entzündlichen Prozeß zeigten $24 \%$ pathologische Neopterinwerte im Serum und $37 \%$ falsch positive Neopterinwerte im Harn. Bei 23 Patienten mit entzündlichen Erkrankungen lagen in 55\% die Neopterinkonzentrationen im Serum und in $59 \%$ die Neopterinkonzentrationen im Harn im pathologischen Bereich.

Der Vergleich der Bestimmung des Neopterin im Harn mit einem RIA und mittels HPLC zeigte, daß radioimmunologisch höhere Werte gemessen werden, die darauf zurückzuführen sind, daß mit dem RIA auch nicht-oxidierte Pterine mitbestimmt werden.

Zusammenfassend dürfte Neopterin ein wertvoller biologischer Marker zur Verlaufskontrolle von malignen hämatologischen Erkrankungen oder bei Patienten mit Hypernephromen sein, bei anderen in dieser Studie untersuchten soliden Tumoren konnten jedoch keine zusätzlichen Informationen gewonnen werden.

\section{Introduction}

Pterines are required as cofactors for the hydroxylation of various substrates (1), and the excretion of pterines seems to be associated with cell proliferation. Recently it has been demonstrated that macrophages stimulated with factors (i. e. interferon gamma) from activated T-lymphocytes release large amounts of neopterin (2). Therefore, neopterin is believed to represent a potential marker for biochemical monitoring of diseases caused by or associated with T-lymphocyte activation. Increased urinary neopterin levels have been reported in patients suffering from viral infections (3), autoimmune disorders (4), in patients with acquired immunodeficiency syndrome (5) and in allograft rejection (6). Kokolis \& Ziegler demonstrated increased pterine concentrations in the blood of cancer patients (7), and enhanced urinary excretion of pterines was found in mice bearing Ehrlich ascites tumours (8). Elevated urinary neopterin levels were also reported in various malignant tumours $(9,10)$ and haematological diseases (11).

In the present study serum and urinary neopterin levels were measured in patients suffering from various malignant diseases. Serum and urinary neopterin levels were determined before and after chemo- therapy to evaluate the role of neopterin in monitoring cancer patients. The clinical significance of the well established tumour markers $\alpha$-fetoprotein (AFP) and human chorionic gonadotropin (HCG) was compared to neopterin in testicular cancer patients. Serum and urinary neopterin concentrations were also determined in patients with nonmalignant diseases without any evidence for an inflammatory process and in patients with inflammatory diseases.

In addition, the determination of neopterin excretion in urine specimens by radioimmunological methods (RIA) and high performance liquid chromatography (HPLC) was compared.

\section{Patients and Methods}

Neopterin in serum and urine

Blood was taken in the fasting state, protected from light, and serum samples were stored at $-20^{\circ} \mathrm{C}$ until analysed. Results are reported in nmol/l neopterin. Neopterin concentrations in serum were determined by a commercially available radioimmunoassay kit (neopterin-RIAcid/serum, Henning, BerlinWest, FRG), which employs a double antibody technique with preprecipitated antiserum and [125I]neopterin as tracer. Samples and antiserum were incubated at room temperature for 1 hour, then the tracer solution was added and incubated at room temperature for a further hour. Bound and non=bound tracer were separated by addition of polyethylepe glycol solution ( 60 
$\mathrm{g} / \mathrm{l})$ and centrifugation. Radioactivity of the precipitate was measured in a gammacounter. Concentrations were calculated by standards from 0 to $160 \mathrm{nmol} / 1$.

Urinary neopterin concentrations were measured in the first specimen of daily urine. Urine samples were collected, protected from light, and stored at $-20^{\circ} \mathrm{C}$. Neopterin and creatinine determinations in the specimens were performed by HPLC on reversed phase, using an automated system device (Neopterin System, Varian International A. G., Zug, Switzerland). Urine samples were diluted $1: 6$ with $15 \mathrm{mmol} / 1$ potassium phosphate buffer ( $\mathrm{pH} 7.0)$. Diluted sample $(10 \mu \mathrm{l})$ was injected onto the column and neopterin was quantitated after chromatographic separation by its native fluorescence ( $353 \mathrm{~nm}$ excitation, 438 $\mathrm{nm}$ emission wavelength). Simultaneously, urinary creatinine was measured using the UV-absorbance at $235 \mathrm{~nm}$. Neopterin results are reported in $\mu \mathrm{mol} / \mathrm{mol}$ creatinine.

In addition, urinary neopterin concentrations were measured using a commercially available RIA-kit (neopterin-RIA/urine, Henning, Berlin-West, FRG). Urine samples were determined by the same method as described for the neopterin-RIA/serum after oxidation with $\mathrm{I}_{2}$ for half an hour in the dark.

\section{AFP and HCG concentrations in serum}

AFP concentrations in serum were determined using an enzyme-immunoassay (AFP-EIA Diagnostik Kit, Abbott Laboratories, North Chicago, U.S.A.).

HCG $(H C G+H C G B)$ levels in serum were measured radioimmunologically (HCG-RIA, Serono, Milano, Italy).

\section{Patients}

Serum and urinary neopterin levels were measured in 38 normal controls (male and female subjects aged $18-72$ years with no evidence of cancer or any other disease).

142 previously untreated patients suffering from various malignant diseases were examined. In all cases malignancy was histologically verified: 31 patients with disseminated testicular cancer (8 seminoma and 23 nonseminomatous germ cell tumours), 15 patients with multiple myeloma, 8 patients with prostatic cancer, 11 patients with bladder tumours, 15 hypernephroma patients, 28 patients suffering from malignant haematological disorders ( 7 acute myelocytic leukaemia, 2 chronic myelocytic leukaemia, 19 lymphoma patients) and a group of 34 patients suffering from various other tumours (12 gastrointestinal cancer, 3 melanoma, 11 lung cancer, 6 sarcoma and 2 other carcinoma patients).

In addition, serum and urinary neopterin levels were measured in the following groups: 16 patients after successful removal of the primary testicular tumour and radical retroperitoneal lymphadenectomy and no evidence of metastases in a careful clinical staging; 28 patients with various diseases (cardiovascular diseases, chronic heart failure, emphysema, prostatic hypertrophy, fertility disorders), but no evidence for an inflammatory process; and 23 patients with inflammatory diseases (8 pneumonia, 4 acute bronchitis, 5 pyelonephritis, 3 prostatitis and 3 epididymitis patients). Statistical analysis was performed using Student's t-test.

\section{Results}

\section{Imprecision}

The imprecision (day per day) for the determination of neopterin in serum (RIA) was CV $=8 \%$, in urine (HPLC) CV $=3 \%$, and in urine (RIA) $\mathrm{CV}=9 \%$ respectively.

\section{Neopterin in controls}

In healthy controls mean neopterin levels in serum were $5.3 \pm 1.7(\mathrm{SD}) \mathrm{nmol} / \mathrm{l}$. Mean urinary neopterin levels as determined by HPLC were $139 \pm 40 \mu \mathrm{mol} /$ mol creatinine. The upper limit of the normal range $(\bar{x}+2 \mathrm{SD})$ was taken as $8.7 \mathrm{nmol} / \mathrm{l}$ in serum and 220 $\mu \mathrm{mol} / \mathrm{mol}$ creatinine in urine samples.

\section{Neopterin in malignant diseases}

$48 \%$ of patients with malignant diseases showed elevated neopterin concentrations in serum, and 55\% of patients showed an increased urinary neopterin excretion (fig. 1). Particularly in cases of malignant haematological disorders (leukaemia and lymphoma patients) most patients showed pathological levels of neopterin in serum $(65 \%)$ and urine $(91 \%)$. In hypernephroma patients elevated serum and urinary neopterin levels were found in $71 \%$ and $89 \%$ of cases, respectively (fig. 1). No correlation between the effect
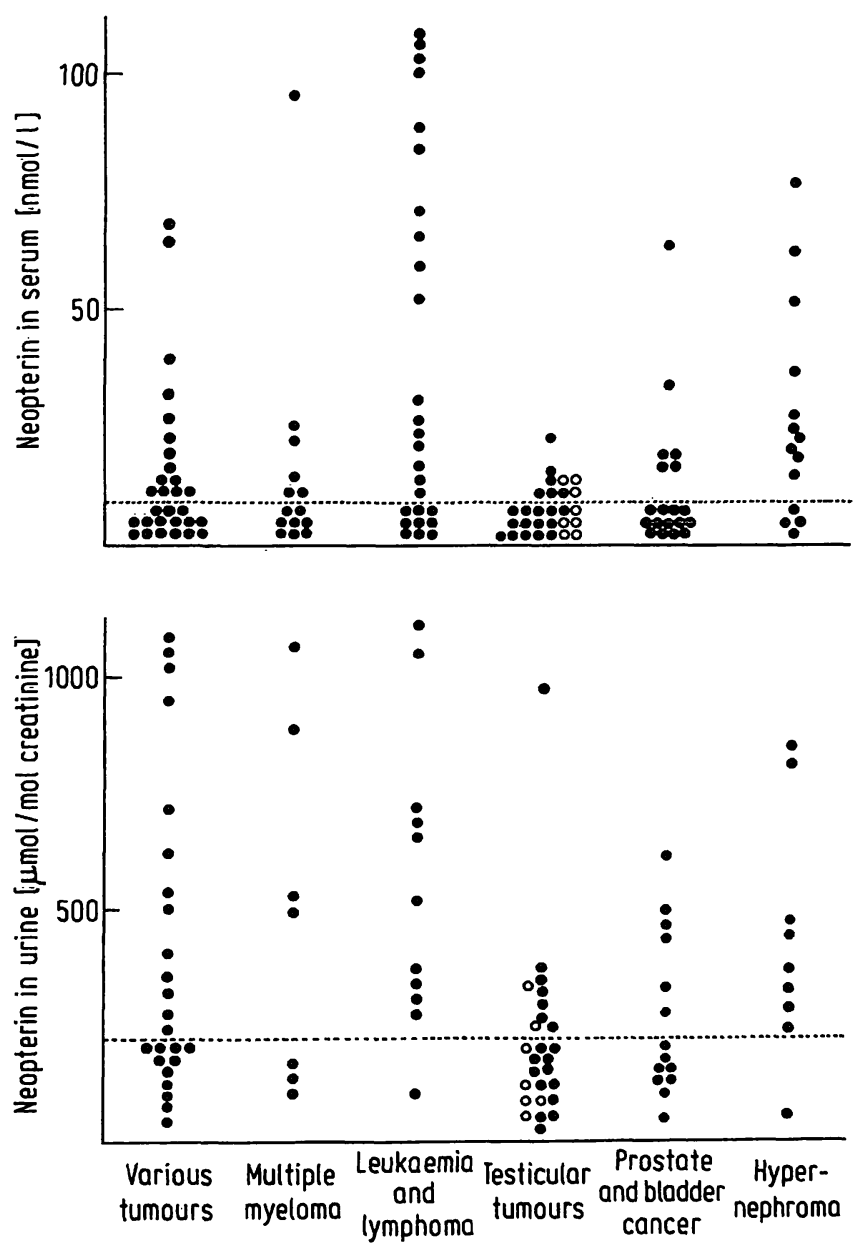

Fig. 1. Serum and urinary neopterin concentrations in various malignant diseases.

.... Upper limit of the reference range $(\bar{x}+2 S D)$. Testicular tumours: o seminoma, o nonseminomatous germ cell tumours. 
of chemotherapy and serum or urinary neopterin levels was found in patients with malignant diseases undergoing chemotherapy. In testicular cancer patients receiving adjuvant chemotherapy, pretherapeutic serum and urinary neopterin concentrations were normal in $93 \%$ and $92 \%$ of cases, respectively. After chemotherapy, $50 \%$ of patients showed elevated serum neopterin levels, and $58 \%$ showed increased urinary excretion rates; neopterin concentrations in serum increased from $5.8 \pm 2.2$ to 12.0 $\pm 7.6 \mathrm{nmol} / \mathrm{l}(\mathrm{p}<0.005)$, and urinary neopterin excretion increased from $98 \pm 34$ to $274 \pm 133 \mu \mathrm{mol} /$ mol creatinine ( $p<0.0005$; fig. 2).

AFP, HCG and neopterin in testicular cancer

Serum AFP, HCG and serum and urinary neopterin levels were compared in testicular tumour patients (tab. 1).

Tab. 1. Increased serum AFP, HCG and serum and urinary neopterin concentrations in testicular cancer patients. (Number of pathological results/total number of patients)

\begin{tabular}{lcccc}
\hline & AFP & $\beta-H C G$ & $\begin{array}{l}\text { Neop- } \\
\text { terin } \\
\text { serum }\end{array}$ & $\begin{array}{l}\text { Neop- } \\
\text { terin } \\
\text { urine }\end{array}$ \\
\hline $\begin{array}{l}\text { Nonseminomatous, } \\
\text { metastasized }\end{array}$ & $14 / 23$ & $13 / 23$ & $6 / 20$ & $7 / 22$ \\
germ cell tumours & & & & \\
$\begin{array}{l}\text { Seminoma } \\
\text { "Adjuvant"*) }\end{array}$ & $0 / 8$ & $3 / 8$ & $3 / 8$ & $1 / 7$ \\
\hline
\end{tabular}

*) "Adjuvant": patients after orchiectomy and radical retroperitoneal lymphadenectomy, tumour-free.

In metastasized seminoma, 3 patients showed elevated HCG levels in serum, and all patients had normal AFP values. Determination of serum or urinary neopterin concentrations gave no additional information in this patient group.

In nonseminomatous germ cell tumours, the sensitivity of serum or urinary neopterin was about $50 \%$ compared to serum AFP or HCG. Combination of AFP and HCG indicated the presence of metastatic disease in 19 out of 23 patients. In the "adjuvant" testicular tumour patients, known to be tumour free, no false positive AFP or HCG values were observed, whereas 1 patient showed false positive serum and 3 patients showed increased urinary neopterin excretion rates.

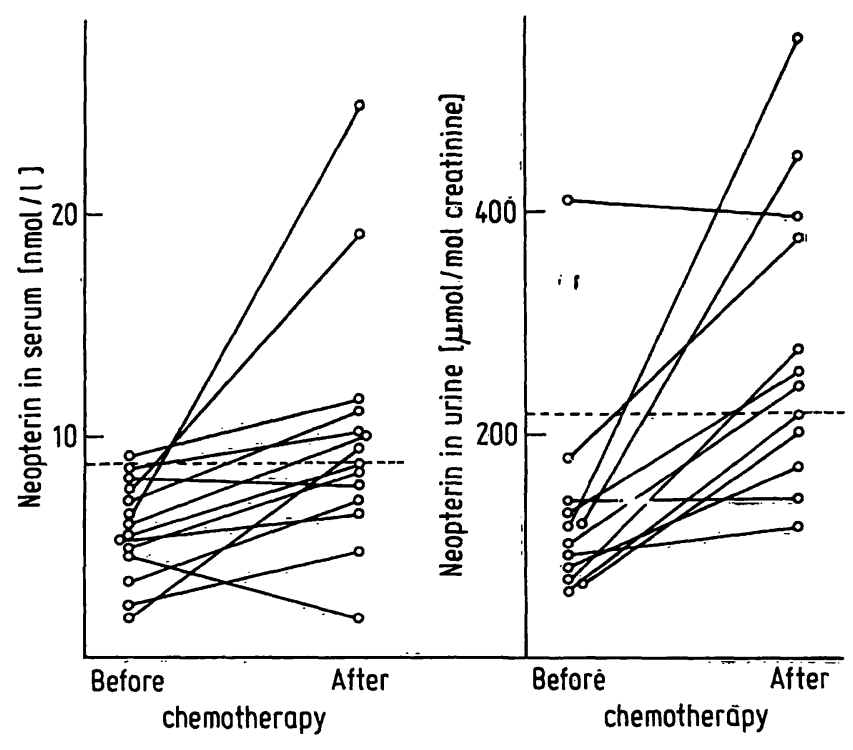

Fig. 2. Serum and urinary neopterin concentrations in testicular cancer patients before and after adjuvant chemotherapy. .... Upper limit of the reference range $(\overrightarrow{\bar{x}}+2 S D)$.

\section{Neopterin in nonmalignant diseases}

Elevated neopterin levels in serum were measured in $24 \%$ of patients suffering from various diseases but showing no evidence for an inflammatory process, and $37 \%$ of these patients showed increased urinary neopterin excretion rates. Pathological serum and urinary neopterin levels were measured in patients with inflammatory diseases in 55\% and 59\% respectively (fig. 3).

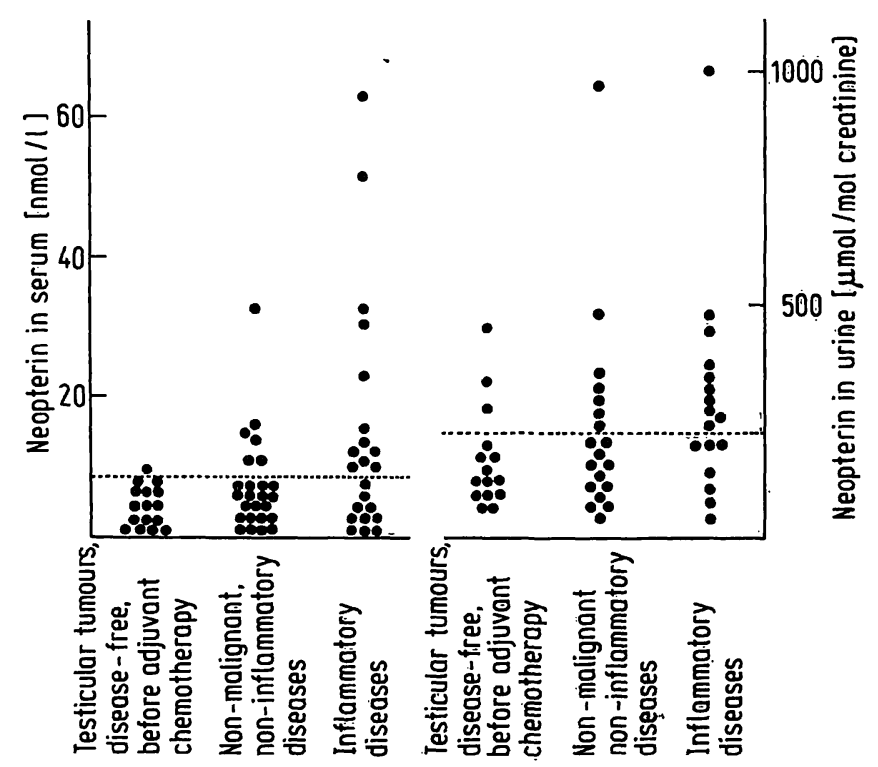

Fig. 3. Serum and urinary neopterin concentrations in tumourfree testicular cancer patients and in nonmalignant noninflammatory and inflammatory diseases.

.... Upper limit of the reference range $(\bar{x}+2 S D)$. 
Comparison of neopterin in urine determined by RIA or HPLC

Comparison of the determination of urinary neopterin concentrations using RIA or HPLC showed a good correlation between both methods (fig. 4), the coefficient of correlation was $\mathbf{0 . 7 8 5}$. However, RIA gave somewhat higher results particularly in urine samples with high neopterin concentrations.

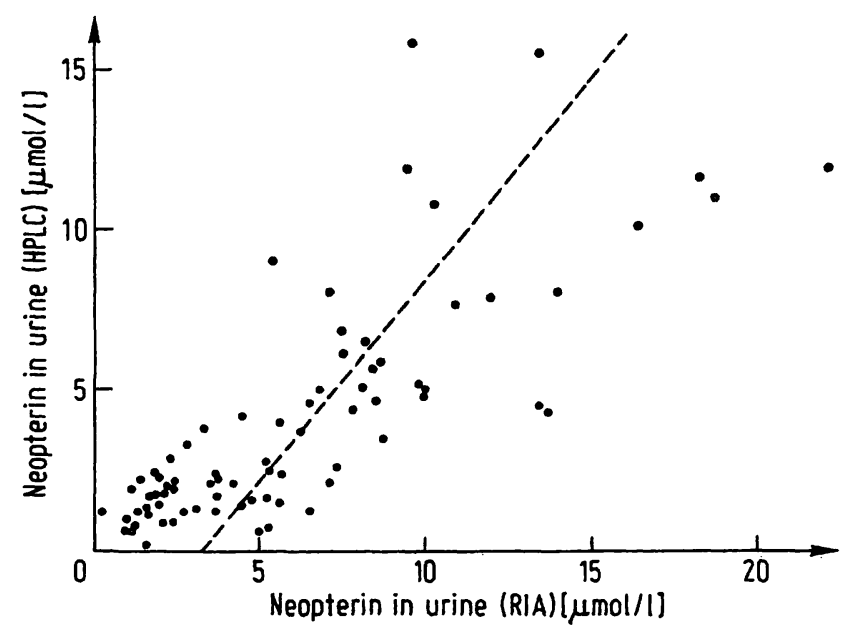

Fig. 4. Determination of urinary neopterin concentrations by HPLC and RIA.

\section{Discussion}

Elevated urinary neopterin excretion rates were reported in a wide variety of malignant diseases, and determination of neopterin is suggested as a useful biochemical marker in monitoring cancer patients $(9$, $10,11)$. Neopterin is believed to be produced by cells involved in the host's immune defense against the tumour, but not by the tumour cells $(2,12)$. In haematological neoplasias the total frequency of elevated urinary neopterin levels was reported to be about $85 \%$ (11). In the present study, the sensitivity of neopterin as a tumour marker in serum and urine was found to be sufficient in haematological malignancies (leukkaemia and lymphoma) and in hypernephroma patients. In our study, the sensitivity of neopterin was rather poor in metastasized testicular cancer patients, in prostate and bladder cancer, as well as in various other solid tumours, all patients being in an advanced stage of the disease, most of them with extensive metastasis.

In the testicular tumour group, consisting of patients after orchiectomy and radical retroperitoneal lymphadenectomy, known to be tumour free, 1 patient showed elevated serum and 3 patients increased urinary neopterin levels. An increase in urinary neopterin excretion rates was reported in patients who had undergone surgery between the third and the sixth day after laparotomy (13). However, in these patients neopterin determinations were performed 4 weeks after lymphadenectomy, and in only 1 patient could the increased urinary excretion rates be explained by an infection in the lymphadenectomy scar.

"False positive" neopterin concentrations were also reported in various non-malignant diseases $(3,9)$ including rheumatoid arthritis (4), tuberculosis (14) as well as during menstruation (15). In accordance with these findings we found increased serum and urinary neopterin levels in patients with various nonmalignant diseases. In patients with inflammatory processes "false positive" serum and urinary neopterin values were observed in $55 \%$ and $59 \%$ of patients respectively. Serum neopterin levels rise with increasing serum creatinine concentrations (16), but in the group of patients with non-malignant diseases with and without inflammatory processes all patients had a normal renal function, so that elevated neopterin levels could not be explained by renal diseases or renal insufficiency. The sensitivity of neopterin as a tumour marker is poor in solid tumours, and "false positive" values frequently occur with various diseases and viral infections, including trivial illnesses, such as the common cold (15). This reflects the poor specificity of the marker. Determination of serum or urinary neopterin is of no value for initial screening for cancer patients.

Comparison of neopterin with the well-established tumour markers, AFP and HCG, in testicular cancer, showed that, in accordance with the poor sensitivity, determination of neopterin provides no further information in the diagnostic procedure of testicular cancer patients. Again, false positive neopterin values were measured in the tumour-free testicular tumour group, whereas all patients showed normal AFP or negative HCG values in this group.

In contrast to the findings of Bichler et al. (17), who reported a good correlation between radiotherapy and chemotherapy and urinary neopterin excretion in cancer patients, we found no correlation between the success of chemotherapy and serum or urinary neopterin levels. When testicular tumour patients, known to be tumour free, received adjuvant chemotherapy, a significant increase in serum and urinary neopterin values after chemotherapy was found. Elevated neopterin concentrations were found in the serum of $50 \%$ of patients, and in the urine of $58 \%$ of patients. Therefore, determination of neopterin is 


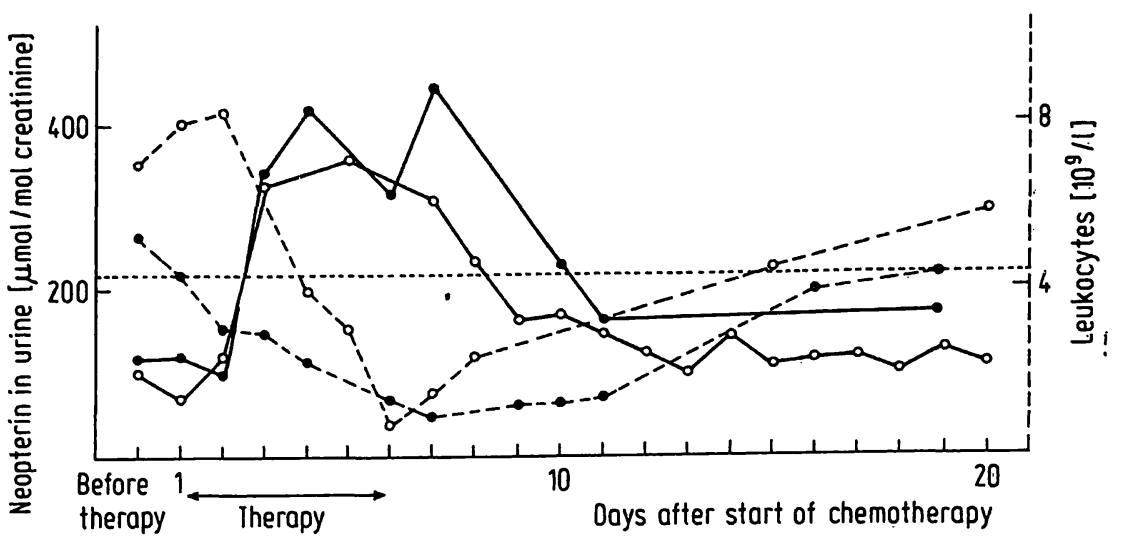

Fig. 5. Urinary neopterin excretion and white blood cell counts in 2 testicular cancer patients receiving adjuvant chemotherapy. Chemotherapy consisted of vinblastine/ bleomycin/cis-platinum (18). ..... Upper lishit of the reference range $(\overrightarrow{\mathrm{x}}+2 \mathrm{SD})$.

$\stackrel{0}{0}$ Neopterin

๑------๑ Leukocytes of no value in monitoring the course and effect of chemotherapy in these patients, since neopterin values arise significantly after chemotherapy. Daily determination of serum and urinary neopterin concentrations before, during and after chemotherapy, showed that the decrease in blood leukocyte count was accompanied by an increase in neopterin levels; this indicates that neopterin is released from macrophages during the cell damage caused by chemotherapy (fig. 5).

However, in haematological disorders and in hypernephroma patients the sufficient sensitivity indi- cates that determination of neopterin might be of some value in monitoring these patients.

Determination of urinary neopterin concentrations with a RIA-method compared to HPLC showed a good correlation, but the results obtained with the RIA were higher, particularly when high neopterin concentrations were present in the urine samplè, indicating that non-oxidized pterines (i.e. 7,8 ; dihydroneopterin) were also measured with the RIAmethod. However, the RIA for neopterin represents an attractive alternative if the HPLC-equipment is not available in the laboratory.

\section{References}

1. Kaufmann, S., Berlow, S., Summer, G. K., Milstien, S., Schulman, J. D., Orloff, S., Spielberg, S. \& Pueschel, S. (1978) N. Engl. J. Med. 299, 673.

2. Huber, Ch., Batchelor, J. R., Fuchs, D., Hausen, A., Lang, A., Niederwieser, D., Reibnegger, G., Swetly, P., Troppmair, J. \& Wachter, H. (1984) J. Exp. Med. 160, 310-316.

3. Wachter, H., Hausen, A. \& Grassmayr, K. (1979) HoppeSeyler's Z. Physiol. Chem. 360, 1957-1960.

4. Hausen, A., Fuchs, D., Reibnegger, G., Wachter, H., Egg, D. \& Günther, R. (1983) Neopterin as index for activity of disease in patients with rheumatoid arthritis. In: Biochemical and Clinical Aspects of Pteridines, 2, (Curtius, H. Ch., Pfleiderer, W. \& Wachter, H., eds.) Walter de Gruyter: Berlin, New York, pp. 245-254.

5. Wachter, H., Fuchs, D., Hausen, A., Huber, Ch., Knosp, O., Reibnegger, G. \& Spira, T. J. (1983) Hoppe-Seyler's Z. Physiol. Chem. 364, 1345-1346.

6. Margreiter, R., Fuchs, D., Hausen, A., Huber, Ch., Reibnegger, G., Spielberger, M. \& Wachter, H. (1983) Transplantation $36,650-653$.

7. Kokolis, N. \& Ziegler, J. (1977) Cancer Biochem. Biophys. $2,79-85$.

8. Wachter, H., Graßmayr, K. \& Hausen, A. (1979) Cancer Lett. 6, 61-66.

9. Rokos, H., Rokos, K., Frisius, H. \& Kirstaedter, H. J. (1980) Clin. Chim. Acta 105, 275-286.

10. Stea, B., Halpern, R. M., Halpern, B. C. \& Smith, R. A. (1981) Clin. Chim. Acta 113, $231-242$.

11. Hausen, A., Fuchs, D., Grünewald, K., Huber, H., König, K. \& Wachter, H. (1982) Clin. Biochem. 15, 34-37.

12. Huber, Ch., Fuchs, D., Hausen, A., Margreiter, R., Reibnegger, G., Spielberger, M. \& Wachter, H. (1983) J. Immunol. 130, 1047-1050.

13. Hausen, A. \& Wachter, H. (1982) J. Clin. Chem. Clin. Biochem. 20, 593-602.

14. Fuchs, D., Hausen, A., Knosp, O., Reibnegger, G., Wachter, H., Hofler, M., Kosanowski, H., Huber, Ch. \& Niederwieser, D. (1983) Neopterin evaluation in patients suffering from pulmonary tuberculosis. In: Biochemical and Clinical Aspects of Pteridines, 2, (Curtius, H. Ch., Pfleiderer, W. \& Wachter, H., eds.) Walter de Gruyter: Berlin, New York, pp. $281-291$.

15. Rokos, K. \& Rokos, H. (1982) Pteridines as tumour markers? An attempt of evaluation by HPLC and radioimmunoassay for neopterin. In: Biochemical and Clinical Aspects of Pteridines, 1, Walter de Gruyter: Berlin, New York, pp. 117-130.

16. Rokos, K. \& Rokos, H. (1983) Pteridines in cancer and other diseases. In: Chemistry and Biology of Pteridines. (Blair, J. A., ed.) Walter de Gruyter: Berlin, New York. pp. $153-157$.

17. Bichler, A., Fuchs, D., Hausen, A., Hetzel, H., König, K. \& Wachter, H. (1982) Clin. Biochem. 15, 38-40.

18. Einhorn, L. H. \& Donohue, J. P. (1977) Ann! Intern. Med. 87, 293-298.
Dr. Rudolf Kuzmits

II. Department of Medicine

Garnisongasse 13

A-1090 Vienna 


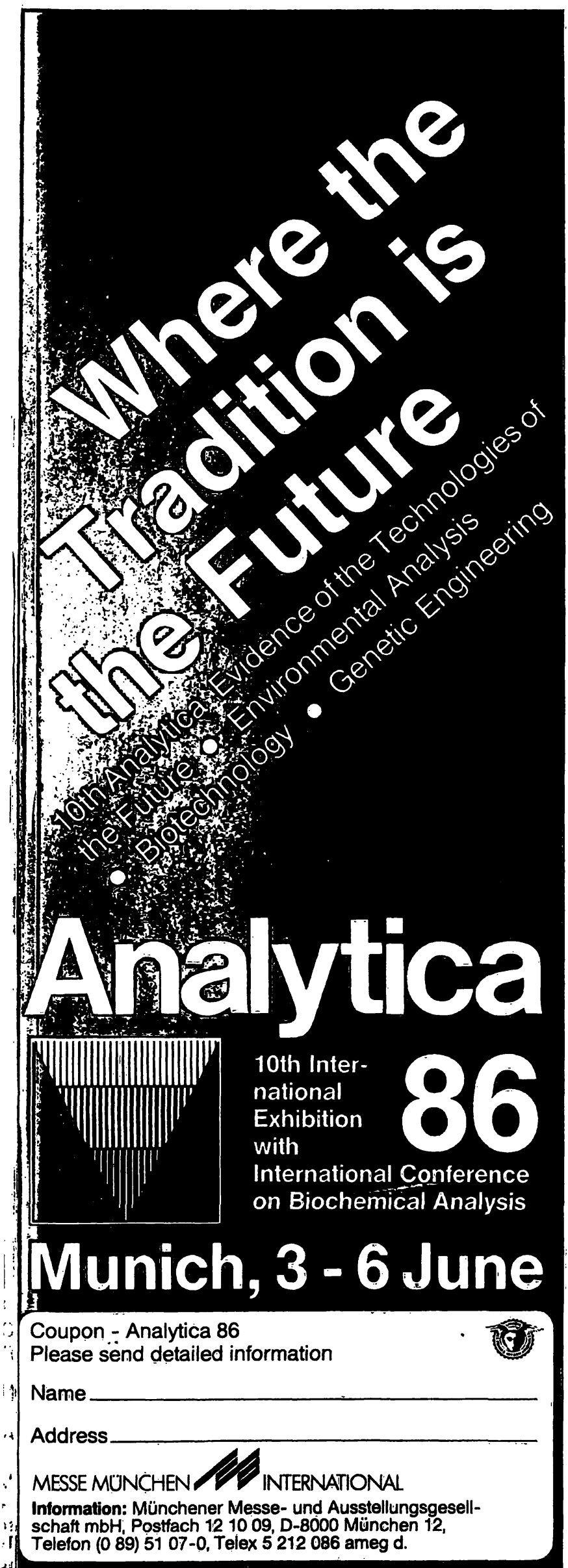

\section{Das spezifische Stoffwechsel-Monitoring für Diabetes}

Weitstrevende aktuelle Blutzuckerwerte können die Einstellung und die Kontrolle des Diabetikers stark erschweren.

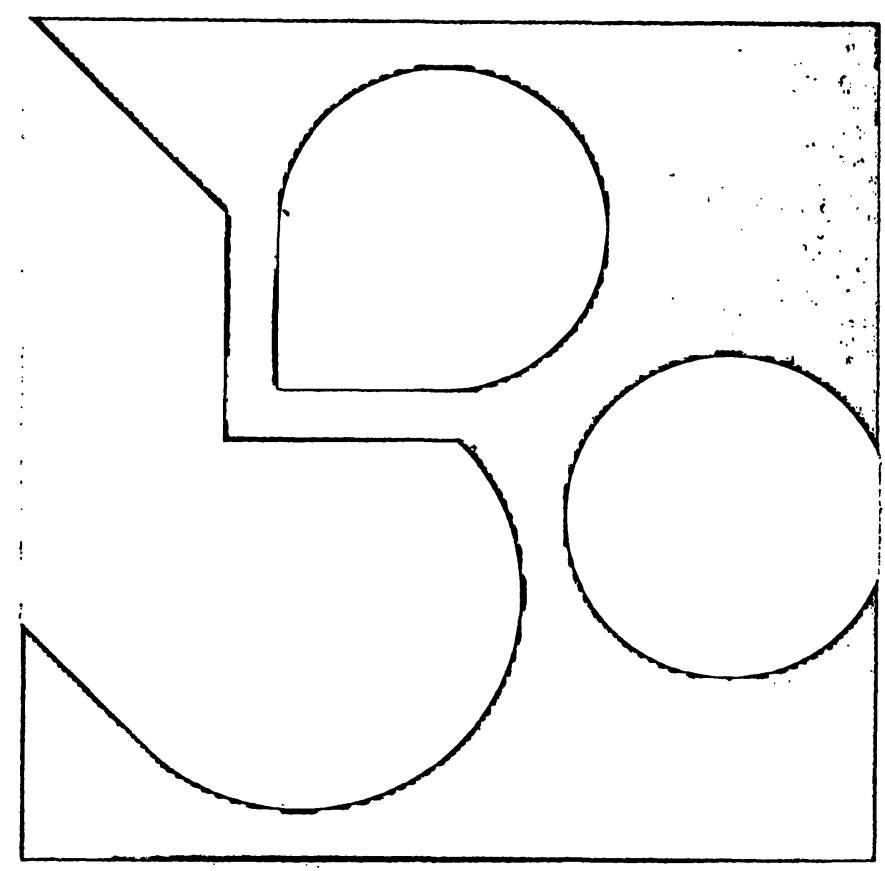

Glyc-Hb stellt das Langzeitgedächtnis der Glucose dar. Mit der affinitätschromatografischen Methode sind eine Reihe von Vorteilen verbunden:

- Einfache Handhabung

- Weitgehende Interferenzfreiheit

- Großer numerischer Unterschied zwischen Werten im pathologischen und Normalbereich

Die Säule ist neunfach regenerierbar.

Alle Komponenten des Merckotest ${ }^{\oplus}$ und MERCK System Glyc-Hb sind aufeinander abgestimmt und einzeln erhältlich.

Weitere Informationen senden wir Ihnen auf Wunsch gerne zu. 


\section{【rnmunnoassay Technology Volume il}

Editor S. B. Pal

1985. $17 \mathrm{~cm} \times 24 \mathrm{~cm}$. VIII, 192 pages. With numerous illustrations. Soft cover. DM 118,-; approx. US $\$ 53.75$

ISBN 3110100622

This is the first volume of a series on Immunoassay Technology which includes Review Articles and Methods and deals essentially with immunological methods of biological, commercial and environmental importance, without introducing radioactive isotopes.

Contents (Main Chapters)

Recent Developments in Measuring Urinary Constituents by Non-Isotopic Immunoassay Techniques - Enzyme Immunoassay for Determination of Pancreatic Glucagon in Plasma - Recent Advances in Isoelectric Focusing Theory, Technique, and Applications of Value in Immunology and Related Disciplines - A New Fluoroimmunoassay of Biopterin and Neopterin in Human Urine - Luminescence Immunoassay in Theory and Practice - The State of the Art - Non-Isotopic Immunoassay for the Estimation of Steroid Hormones - Contributors - Notes on Contributors · Subject Index 